\title{
Pleomorphic Adenoma of Parotid Gland: A Case Report \& Review of Literature
}

\author{
Dr. Shreyas N. Shah ${ }^{1}$, Dr. Priyank R. Mistry ${ }^{2}$, Dr. Kapil Dagrus ${ }^{3}$, \\ Dr. Vandana Shah ${ }^{4}$, Dr. Uday N. Patel ${ }^{5}$, \\ ${ }^{I}$ Reader, Department Of Oral Pathology, K. M. Shah Dental College And Hospital, Sumandeep Vidyapeeth, \\ Vadodara, Gujarat. \\ ${ }^{2}$ Senior Resident, Department Of ENT., Parul Institute Of Medical Sciences And Research, Vadodara, Gujarat. \\ ${ }^{3}$ Senior Lecturer, Department Of Oral Pathology, K.M. Shah Dental College And Hospital, Sumandeep \\ Vidyapeeth, Vadodara, Gujarat. \\ ${ }^{4}$ Professor And Head Of Department, Department Of Oral Pathology, K.M. Shah Dental College And Hospital, \\ Sumandeep Vidyapeeth, Vadodara, Gujarat. \\ ${ }^{5}$ Reader, Department Of Oral Pathology, Goenka Research Institute Of Dental Sciences, Gandhinagar, Gujarat.
}

\begin{abstract}
Overall salivary gland tumours are rare, comprising of less than 3\% of overall head and neck neoplasms. Parotid gland is the most common site for the benign salivary gland neoplasm. Usually they are painless slow growing lesion involving the superficial or deep part of the gland and can severely affect the facial nerve functioning. Treatment mainly comprises of surgical excision with preservation of the facial nerve. A 28 year old female presented with painless swelling in the left parotid region since 2 years. The C.T. scan shows a hyperdense circumscribed mass involving the left parotid gland. On surgical exploration the neoplasm was resected and histopathologically diagnosed as Pleomorphic adenoma of parotid. It is of clinical significance to rule out other different benign and malignant neoplasm present in the parotid region for the proper diagnosis and management of these types of lesion encountered in routine dental practice.
\end{abstract}

Keywords: Pleomorphic adenoma, Benign tumour, parotid gland, parotidectomy.

\section{Introduction}

Salivary gland neoplasms are very rare and comprise almost $3 \%$ of overall head and neck tumours. ${ }^{[1]}$ Pleomorphic adenoma is the most common benign tumour encountered in salivary glands and accounting for approximately $60 \%$ of all the salivary gland neoplasms. ${ }^{[2]}$

The most common site for pleomorphic adenoma is parotid gland and form $60-70 \%$ of all the parotid tumours. Incidence of this tumour is about 2.4 in 1,00,000 per year. Although benign, size ranges from very small to enormously huge. Mostly females are affected with a ratio of $2: 1 .^{[3,4,5]}$ In this case report we present a case report of pleomorphic adenoma involving the superficial lobe of parotid gland.

\section{Case History}

A 28 year old female came with a complaint of slowly growing painless mass on the left side of the face just below the ear region [Figure 1]. No significant medical history. On clinical examination the swelling was painless, measuring about $2 \mathrm{~cm} \times 3 \mathrm{~cm}$ in size, situated in the lower pole of the left parotid gland [Figure1]. On palpation the swelling is well defined, non tender, soft to firm in consistency and not adherent to the underlying skin. No involvement of Facial nerve.

Computed tomography of the lesion showed a large well defined, encapsulated, homogenously hyperdense large mass measuring approximately $4 \mathrm{~cm} \times 3 \mathrm{~cm}$, involving the left parotid gland [Figure 2].

Based on the clinical and radiological examination a provisional diagnosis of pleomorphic adenoma is considered. The lesion was surgically excised by superficial parotidectomy with the preservation of the facial nerve [Figure 3].

Macroscopically, specimen was irregular lobulated mass with well defined borders having irregular capsule [Figure 4].Further histopathological examination showed presence of thick fibrous dense capsule around the gland [Figure 5]. Higher magnification showed presence of myoepitheial and ductal cells arranged in form of cords and sheets along with myxoid areas [Figure 6]. Few areas showed the early chondroid like changes [Figure 7]. 


\section{Discussion}

Pleomorphic adenoma [P.A.] or benign mixed tumour is known to be most common salivary gland neoplasm. The most common site of occurrence is the parotid gland. ${ }^{[3,4,5]}$ The P.A. of parotid gland is more common that the accessory salivary gland. The most common site for accessory gland P.A. observed is the palatal salivary glands. ${ }^{[6]}$ Classical Parotid tumour present just below the lobule of the ear, above the angle of the mandible. ${ }^{[3,4]}$ In present case the site of occurrence is concurrent with the literature [Figure 1].

Most commonly the P.A. occurs in the young and middle age group mainly between $3^{\text {rd }}-4^{\text {th }}$ decade of life with females, the most commonly affected. ${ }^{[7]}$ Although the tumour is benign in nature but it can range from very small to very huge in size. ${ }^{[8,9]}$

Macroscopic features of the tumour shows mainly irregular, multinodular lesion with the bosselated surface with the complete or incomplete capsule like structure. The surface is firm in nature and presence of softness in nodule is suggestive of cystic degeneration of the lesion. ${ }^{[10]}$ In our present case all the macroscopic features are concurrent with the literature reviewed [Figure 4].

The radiographic features are important in diagnosis of pleomorphic adenoma. Mostly the benign tumors shows an hyperdense image on the C.T. scan of the lesion. ${ }^{[11]}$ In our case also a hyper dense image is present within the structure of the parotid gland [Figure 2]

Pathogenesis of P.A. is related to mainly involvement of myoepithelial cells and reserve cells present in the intercalated duct. It is proposed that these altered neoplastic cells are responsible for multidirectional differentiation of this mixed benign tumour. ${ }^{[12]}$ Recently the molecular analysis of the tumour shows the involvement of pleomorphic adenoma gene (PLAG1) on chromosome 8 and various cytogenetic abnormalities of translocations involving $12 \mathrm{q} 15 .{ }^{[13,14]}$

The histopathological spectrum of pleomorphic adenoma is variable and consists of primarily two components, stromal and cellular. The cellular components primarily comprised of glandular epithelium cells and myoepithelial cells. Myoepithelial cells show variation in shape ranging from angular or spindle shape, round with eccentric nuclei or hyalinised with eosinophillic cytoplasm (plasmacytoid) appearance. ${ }^{[15]}$

Extracellular stroma is prominent component of the P.A., can present very sparse to abundance and can show variable form: myxoid, chondroid, chondro-myxoid, hyaline, fibrous, sclero-hyaline and, very rarely, osseous and adipose. ${ }^{[12,16]}$ Seifert subclassified P.A. on the basis of relative proportion of stromal and cellular components in to four subtypes. ${ }^{[17]}$

Type I : (stroma comprises $30-50 \%$ of the tumor),

Type II : (stroma comprises $\sim 80 \%$ of the tumor),

Type III : (stroma comprises $~ 20-50 \%$ of the tumor) and

Type IV : (stroma attains similar proportion to that of type III, but there is focal monomorphic differentiation in the epithelial component). In our case also few areas showed the presence of chondroid like areas [Figure 7].

Surgical excision is the treatment of preference for P.A. and may vary from enucleation to superficial or total parotidectomy. Superficial parotidectomy along with adequate excision of capsule is the treatment of choice for the P.A. of the superficial lobe of parotid. ${ }^{[18,19]}$ Because of the presence of incomplete and thin capsule, the tumour buds may be extended beyond the capsule and responsible for the high recurrence. ${ }^{[20]} \mathrm{A}$ recurrence rate of up to $40 \%$ was noticed in treated cases of P.A. ${ }^{[21]}$ The recurrence is debatable and subjected to the treatment. The main casues for recurrence is believed to be the intra-operative tumour spillage and incomplete resection. ${ }^{[22]}$

Prognosis for P.A. is excellent with a cure rate of $95 \%$. The malignant transformation rate is found to be 1.9-23.3\%. ${ }^{[4]}$ Two main metastatic variant, carcinoma ex pleomorphic adenoma and metastasizing benign mixed tumor are observed. ${ }^{[4]}$

\section{Summary and Conclusion:}

Pleomorphic adenoma mostly appears as slowly growing painless mass. A careful differential diagnosis should be considered to rule out the malignant salivary gland neoplasm occurring in the parotid region. A complete excision with a safe margin reduces the high recurrence rate for this benign neoplasm. Alarming signs like facial nerve involvement along with cystic degeneration in the neoplasm should be considered for early malignant changes. Present case report describes a case of P.A. with emphasis on the different differentials considered prior to sound diagnosis. At most care should be taken for avoid recurrence and malignant transformation.

\section{References}

[1]. Luna MA, Batsakis JG, El-Naggar AK. Salivary gland tumors in children. Ann Otol Rhinol Laryngol 1991;100:869-71.

[2]. Pinkston JA, Cole P. Incidence rates of salivary gland tumors: results from a population based study. Otolaryngol Head Neck Surg 1999;120:834-40

[3]. Silva SJ, Costa GT, Filho ACB, Faria PR, Loyola AM. Metachronous bilateral pleomorphic adenoma of the parotid gland. Oral surgery, Oral Medicine, Oral Pathology, Oral Radiology, and Endodontology. 2006; 101:333-338 
[4]. Jr Takahama A, Perez DEC, Magrin J, Almeida OP, Kowalski LP. Giant pleomorphic adenoma of the parotid gland. Med Oral Patol Oral Cir Bucal 2008; 13: E 58-60

[5]. Shashinder S, Tang IP, Velayutham P,Prepageran N, Gopala KG, Kuljit S et al. A review of parotid tumours and their management: A ten-year- experience. Med J Malaysia 2009; $64: 31-33$

[6]. Boko E, Napo-Koura G, Kpemissi E and Boko-Bessi L. Tumours of the accessory salivary glands.Epidemiological and anatomopathological aspects. Rev Laryngol Otol Rhinol 2004;125:233-7.

[7]. Kusama K, et al Intraoral minor salivary gland tumors: a retrospective study of 129 cases. J Nihon Univ Sch Dent. 1997;39:128-32.

[8]. Hirabayashi S, Yanai A, Muraishi Y. Huge pleomorphic adenoma of the upper retromolar area. Ann Plast Surg. 1997 ;38:184-6.

[9]. Zhao S, Zhao F, Su J. Giant pleomorphic adenoma of the parotid gland: one case report and review of the literature. Lin Chung Er Bi Yan Hou Tou Jing Wai Ke Za Zhi. 2014 ;28:1066-9.

[10]. Sunil S, Gopakumar D. Pleomorphic Adenoma: A Case Report and Review of Literature. Int J Odontostomat. 2013;7:171-174.

[11]. Brunese L, Ciccarelli R, Fucili S, Romeo A, Napolitano G, D'Auria V, et al Pleomorphic adenoma of parotid gland: delayed enhancement on computed tomography. Dentomaxillofac Radiol. 2008 ;37:464-9.

[12]. Ellis GL, Auclair PL: Malign epithelial neoplasms. In: Tumors of the salivary glands. Atlas of Tumor Pathology. 4 edition. Washington, DC: Armed Forces Institute of Pathology; 2008, 173-439

[13]. Voz ML, Agten NS, Van de Ven WJ, Kas K. PLAG1, the main translocation target in pleomorphic adenoma of the salivary glands, is a positive regulator of IGF-II. Cancer Res. $2000 ; 60: 106-13$.

[14]. Voz ML, Van de Ven WJ, Kas K. First insights into the molecular basis of pleomorphic adenomas of the salivary glands. Adv Dent Res. $2000 ; 14: 81-3$.

[15]. Mărgăritescu C, Raica M, Simionescu C, Mogoantă L, Surpăţeanu M, Jaubert F, et al Tumoral stroma of salivary pleomorphic adenoma -- histopathological, histochemical and immunohistochemical study. Rom J Morphol Embryol. 2005;46:211-23.

[16]. Haskell H. D.,Butt K. M., Woo S. B., Pleomorphic adenoma with extensive lipometaplasia: report of three cases, Am J Surg Pathol, 2005; 29:1389-1393.

[17]. Seifert G., Miehlke A., Haubrich J., Chilla R., Diseases of the salivary glands: diagnosis, pathology, treatment, facial nerve surgery, Georg Thieme Verlag, Stuttgart, 1986, 65-130.

[18]. Laskawi R, Schott T, Mirzaie-Petri M, Schroeder M. Surgical management of pleomorphic adenomas of the parotid gland: a followup study of three methods. J Oral Maxillofac Surg. 1996 ;54:1176-9.

[19]. Webb AJ, Eveson JW. Pleomorphic adenomas of the major salivary glands: a study of the capsular form in relation to surgical management. Clin Otolaryngol Allied Sci. 2001;26:134-42.

[20]. Witt RL. The significance of the margin in parotid surgery for pleomorphic adenoma. Laryngoscope. 2002;112:2141-54.

[21]. Koral K, Sayre J, Bhuta S, Abemayor E, Lufkin R. Recurrent pleomorphic adenoma of the parotid gland in pediatric and adult patients: value of multiple lesions as a diagnostic indicator. AJR Am J Roentgenol. 2003;180:1171

[22]. O'Brien CJ. Current management of benign parotid tumors-the role of limited superficial parotidectomy. Head Neck. 2003;25:94652.

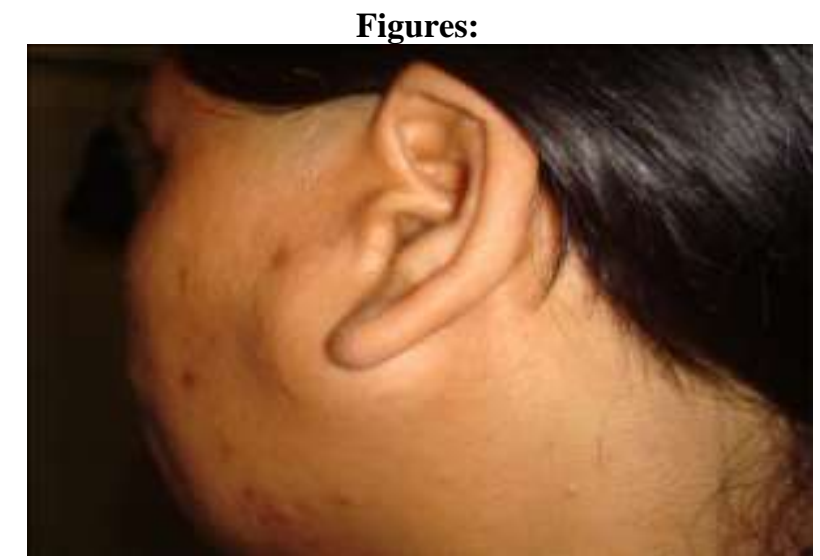

Figure 1: Clinical photograph showing the swelling at the left parotid region

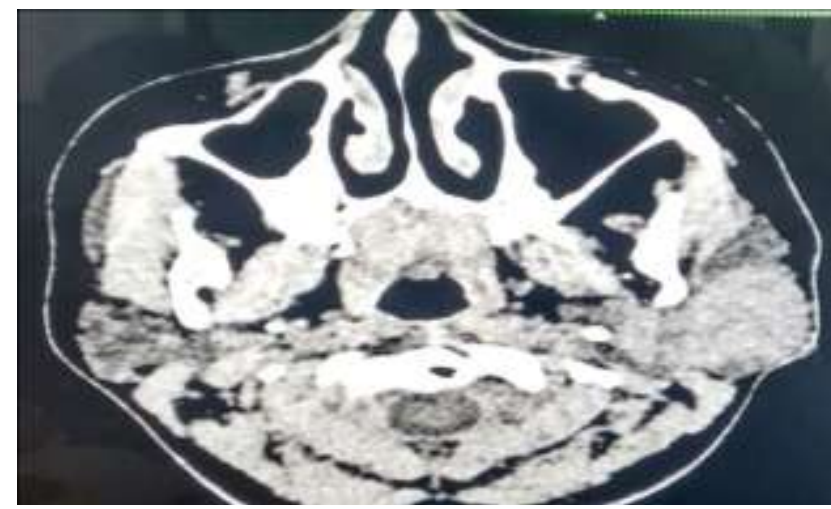

Figure 2: CT image showing a well-defined hyperdense homogenous lesion in the Parotid gland 


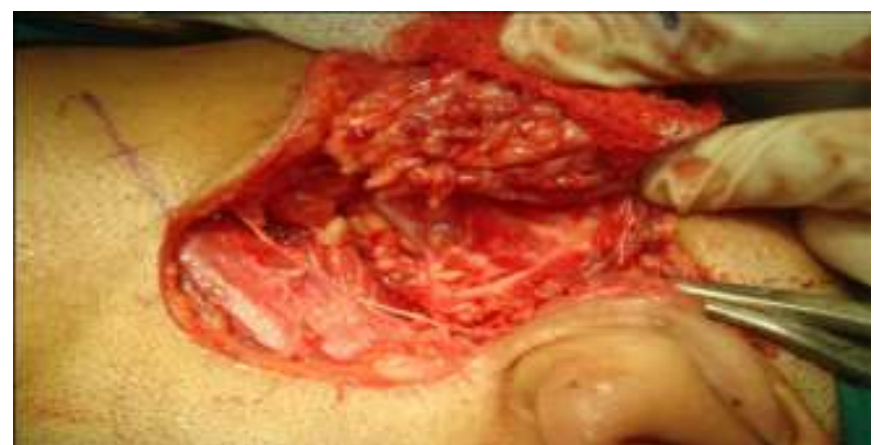

Figure 3: Intraoperative image showing the presence of neoplasm after surgical exposure

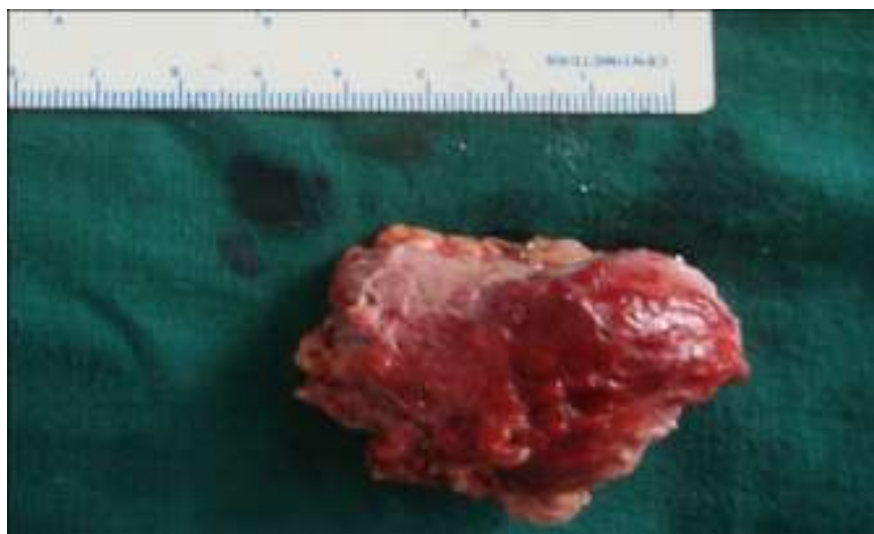

Figure 4: The surgical specimen showing lobulated appearance with typical bosselated surface.

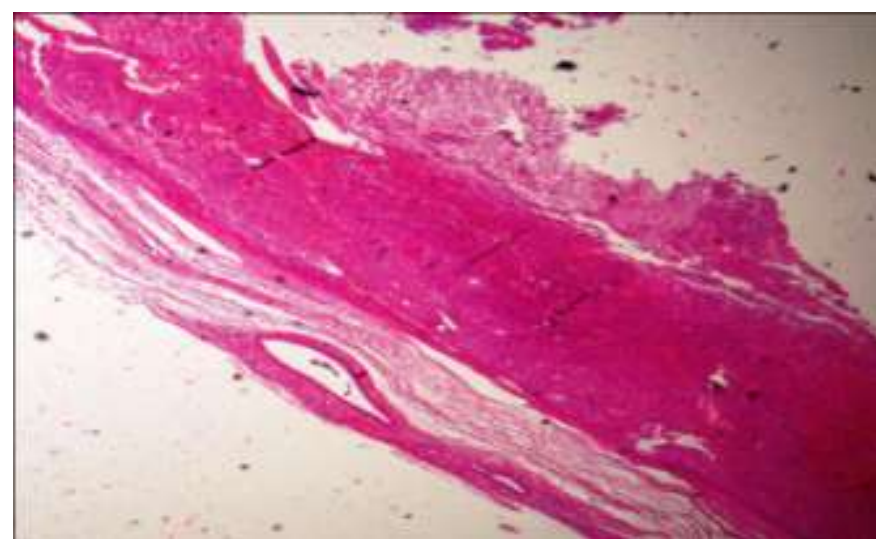

Figure 5: photomicrograph showing thick fibrous dense capsule like condensation (10X)

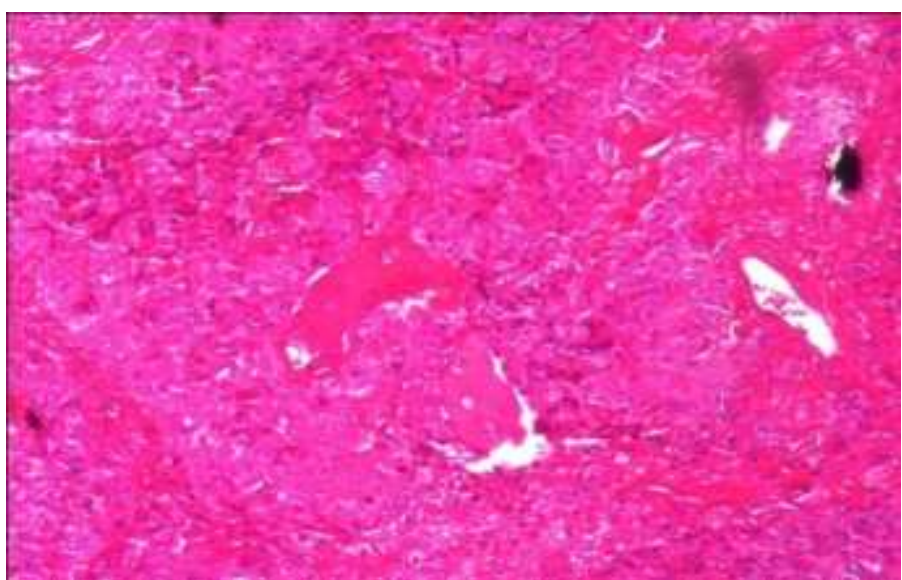

Figure 6: photomicrograph showing proliferation of myoepithelial cells (40x) 


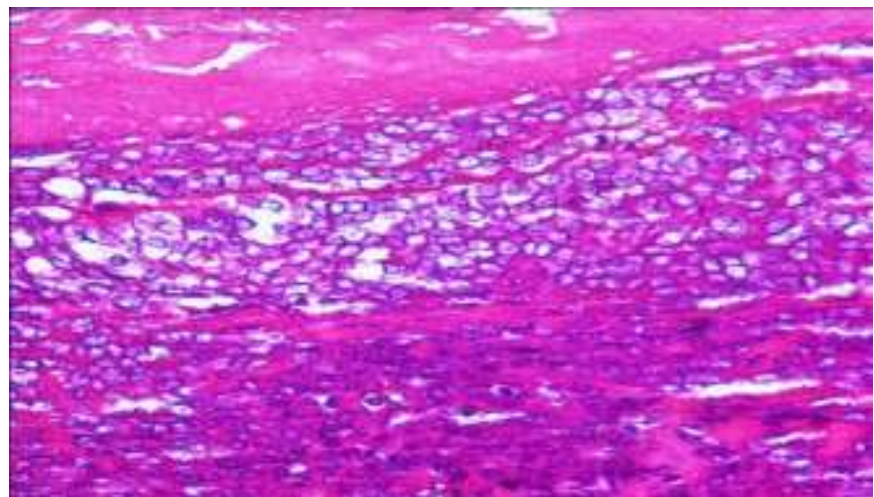

Figure 7: photomicrograph showing cartilage like areas (40x)

Tables:

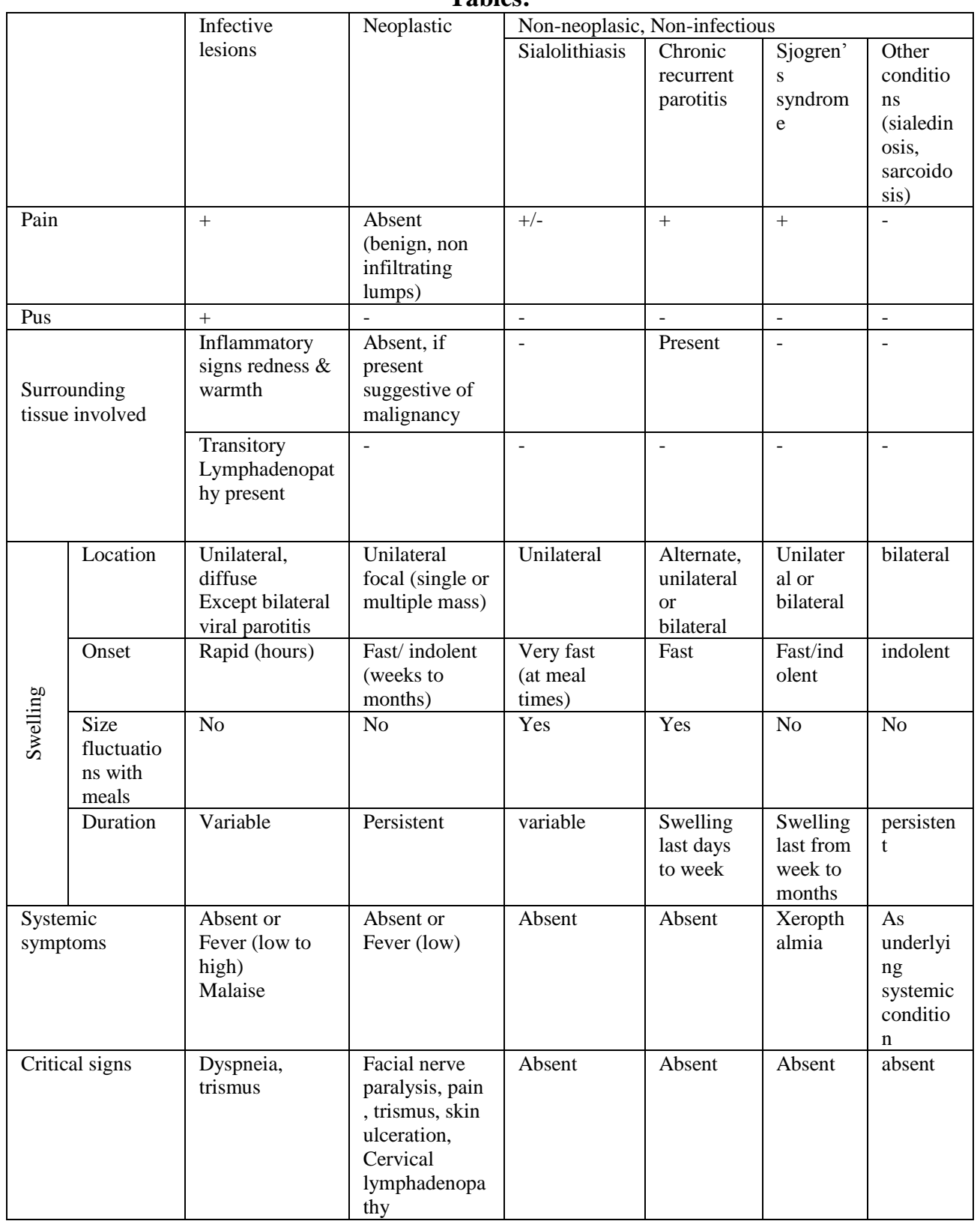

Table 1: Table showing different differential diagnosis considered for parotid swelling 